\title{
Minimal invasive percutaneous plate osteosynthesis (MIPPO) through deltoid- pectoralis approach for the treatment of elderly proximal humeral fractures
}

\author{
Li Zhao ${ }^{\dagger}$, Peng Yang ${ }^{\dagger}$, Lei Zhu ${ }^{\dagger}$ and Ai-min Chen ${ }^{*}$
}

\begin{abstract}
Background: Current treatments for proximal humeral fractures include conservative treatment, conventional open reduction internal fixation (ORIF) and MIPPO through deltoid-splitting approach. The aim of this study was to evaluate the clinical outcome of MIPPO versus ORIF via the deltoid-pectoralis approach in elderly patients with proximal humeral fractures.

Methods: Thirty-six patients with proximal humeral fractures were enrolled in this study. Following the randomized block and single-blinded principle, the patients were assigned to two groups and treated with either conventional ORIF or MIPPO, both through the deltoid-pectoralis approach. Surgical outcomes were evaluated by the NEER score, Constant-Murley score, blood loss, length of operation, radiological imaging and clinical examination. The patients were followed up for 4-24 (mean 10) months.

Results: According to Constant-Murley score, the surgical outcome was excellent in 14 cases, satisfactory in 2 cases and unsatisfactory in one case in MIPPO group versus 10,5 and 4 in conventional ORIF group. MIPPO was significantly advantageous over conventional ORIF in terms of NEER score, Constant-Murley, length of operation and intraoperative blood loss. In addition, MIPPO was also more advantageous in several indexes in patients with BMI > 26.0 and NEER type III fracture.
\end{abstract}

Conclusion: The results of our study have demonstrated that MIPPO through the deltoid-pectoralis approach is an effective alternative for the treatment of proximal humeral fractures in elderly patients.

Trial registration: The trial registration number (TRN): ChiCTR-INR-17011098 (retrospectively registered at 2017-04-09)

Keywords: Minimal invasive percutaneous plate osteosynthesis (MIPPO), Deltoid-pectoralis approach, Proximal humeral fractures

\section{Background}

With the aging of society, osteoporosis-related fracture and its comorbidities including pneumonia, deep vein thrombosis (DVT), limb dysfunction, nerve injury and decubitus in elderly people have increasingly become major medical concerns in China [1, 2]. Proximal humeral fracture (PHF), which consists of $5 \%$ of all frac-

\footnotetext{
* Correspondence: aiminchen@aliyun.com

${ }^{\dagger}$ Equal contributors

Department of Orthopedic Trauma Surgery, Changzheng Hospital, the Second Military Medical University, 415 Feng Yang Rd., Huang Pu district, Shanghai 200003, China
}

tures, increased by more than 3 fold between 1970 and 2002, and about $70 \%$ of all 3/4-part PHF were seen in patients over 60 years [3-5]. Among conservative treatment, open reduction internal fixation (ORIF), minimal invasive percutaneous plate osteosynthesis (MIPPO), intramedullary nailing and arthroplasty reported in literature [6-14], which is the optimal treatment for PHF remains controversial. Due to poor bone quality, complications such as anemia, infection and delayed union are more common in elderly patients [15]. Conventional surgical methods of ORIF include the lateral deltoid approach and the deltoid-pectoralis approach. However, 
the lateral deltoid approach using the MIPPO technique was recently reported to associated with a risk of damage to blood supply of the deltoid and axillary nerve [4, 11, 15-28]. Compared with this approach, the deltoidpectoralis approach requires extensive soft tissue reduction and may damage the anterior circumflex humeral artery and cephalic vein [16].

To provide an alternative option for the treatment of PHF in elderly patients, we for the first time used the MIPPO technique through the deltoid-pectoralis approach with the proximal humeral internal locking system to treat elderly PHF. The aim of the present study was to verify the advantages of the MIPPO technique through the deltoid-pectoralis approach by comparing the clinical outcomes of 17 cases treated with this technique and 19 cases treated with conventional ORIF through the deltoid-pectoralis approach in terms of NEER/Constant-Murley Score, intraoperative blood loss, length of operation and union time.

\section{Methods}

Included in this study were 36 patients who attended our department for PHF between August 2014 and June 2016. The inclusion criteria included: (1) patients with freshly diagnosed PHF (NEER II/III); (2) patients with surgical indications; and 3) patients older than 55 years. Patients were excluded from the study if they: (1) had severe systemic diseases; (2) pathological fractures; and (3) primary neurovascular damage.

All the 36 patients in this prospective study were diagnosed as unilateral PHF and individually divided into MIPPO $(n=17)$ and ORIF $(n=19)$ groups with the principle of randomized block. All fractures were classified according to NEER classification based on X-ray and CT presentations (Fig. 1a). There were 15 cases of NEER II PHF and 21 cases of NEER III PHF (Table 1).

On admission, all the patients received routine treatments including hemostasis, detumescence, analgesia, temporary fixation and blood/imaging examinations.
The mean time from injury to operation was 2.7 days. In MIPPO group, the patient was laid in a beach position and an approximately $5 \mathrm{~cm}$ incision was made along the coracoid process of the scapula below the pectoraldeltoid clearance under general anesthesia. The cephalic vein was then exposed and protected with caution. After properly isolating the soft tissue and sternoclavicular fascia, the humeral head was exposed. A 2-cm skin incision was made longitudinally underneath the proximal incision. The bone block was reduced and provisionally fixed by Kirschner wires as confirmed by fluoroscopy. Then, a subcutaneous tunnel was made from both incisions to the fracture site over the periosteum deep to the deltoid muscle and an ITS proximal humeral locking plate (GE medical, USA) was inserted from the proximal incision and adjusted to a suitable height. A screw was fixed at both proximal and distal ends of the plate separately. If the X-ray image proved that the position of the fracture end and the plate were acceptable, 4-5 screws were fixed proximally while 2-3 screws were fixed distally (Fig. 1b). Allograft bone was grafted if there existed bone loss. No allograft was grafted in all 36 patients of the present study. After checking surgical instruments and irrigation, the incisions were closed.

In conventional ORIF group, the patient was laid in the same position and received conventional surgery through the deltoid-pectoralis approach. An approximately $12-\mathrm{cm}$ incision was made along the medial border of the deltoid muscle from the coracoid process of the scapula. After proper exposure of the soft tissue and muscle according to the fracture site, the fracture was carefully reduced and fixed by Kirschner wires. Similar to MIPPO group, an ITS proximal humeral locking plate (GE Medical, USA) was gently inserted and screws were fixed based on real time X-ray imaging. The length of operation and intraoperative blood loss were recorded during surgery. Two groups shared the same type of surgical instruments, plates and screws and were conducted by Prof. Chen AM.
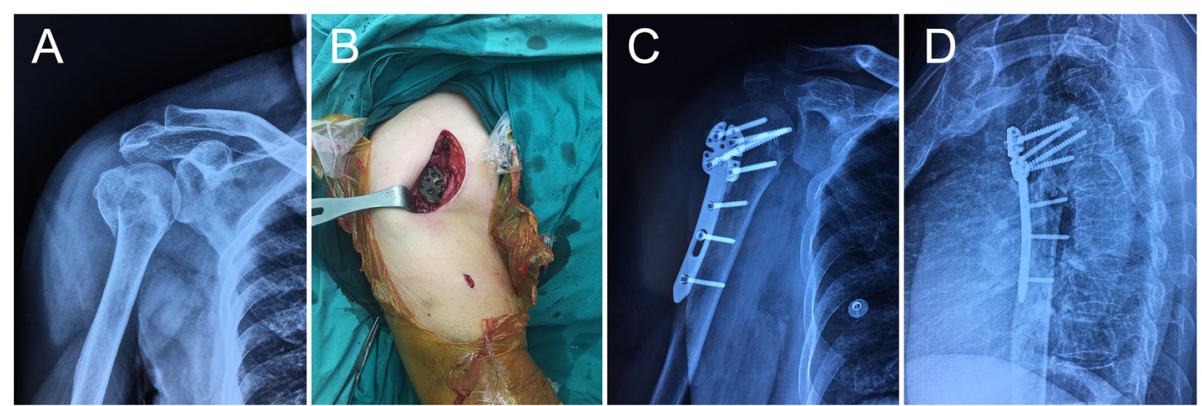

Fig. 1 Follow-up data of a 66-year-old female. a Pre-operative X-ray shows an unstable right proximal humeral fracture. $\mathbf{b}$ intraoperative incisions (a 5-6 cm incision and a $1 \mathrm{~cm}$ incision). c/d Post-operative X-rays in in anteroposterior and lateral views show a good reduction and proper placement of the plate 
Table 1 Demographics of the patients

\begin{tabular}{|c|c|c|c|c|c|}
\hline Characteristic & & Value & MIPPO group & ORIF group & $P$ value \\
\hline Gender & $M / F$ & $21 / 15$ & $9 / 8$ & $12 / 7$ & 0.548 \\
\hline Age & Average $\pm S D$ & $64.0 \pm 5.8$ & $64.3 \pm 6.7$ & $63.6 \pm 5.0$ & 0.759 \\
\hline $\mathrm{BMI}\left(\mathrm{kg} / \mathrm{m}^{2}\right)$ & Average & $25.9 \pm 3.0$ & $26.8 \pm 3.2$ & $25.1 \pm 2.5$ & 0.08 \\
\hline \multirow[t]{3}{*}{ Mechanism } & Traffic accident & 7 & 3 & 4 & \\
\hline & Fall & 17 & 7 & 10 & \\
\hline & Sports & 12 & 7 & 5 & \\
\hline \multirow[t]{2}{*}{ NEER classification } & ॥ & 15 & 8 & 7 & \\
\hline & III & 21 & 9 & 12 & \\
\hline time between injury and operation(days) & Average $\pm S D$ & $2.7 \pm 0.8$ & $2.8 \pm 0.7$ & $2.7 \pm 0.9$ & \\
\hline Follow-up(months) & Average(range) & $10(4-24)$ & & & \\
\hline
\end{tabular}

Patients received routine postoperative treatments, and functional rehabilitation was initiated about 6 days after operation at the time of discharge. Elbow flexion to $90^{\circ}$ and external rotation to $0^{\circ}$ for 4 weeks was suggested to reduce the stretching force of the shoulder joint. Active exercise of the shoulder joint would begin 4 weeks postoperatively depending on the healing situation. Complications were defined as infections, nerve and vascular injuries, decubitus, pneumonia and nonunion. Nonunion was diagnosed when the fracture remained unhealed 9 months after operation and no evidence of healing was observed for subsequent 3 months. Followup visits were arranged monthly in the first 6 months, and then at 24 and 48 months postoperatively for clinical and radiographic examinations. The healing of fracture and complications were evaluated according to the anteroposterior and lateral views of radiography (Fig. 1c and d). Clinical outcomes were evaluated by NEER/Constant-Murley score expressed as mean \pm SD. All 36 patients were able to complete the visual analogue scales (VAS) for pain on their own at the final follow-up. The VAS pain scale ranged from 0 (no pain) to 10 (severe pain), and patients estimated the mean pain level in the injured limb during the previous month (Table 2). The evaluations were accomplished at 6 months postoperatively or at the latest visit in patients who were discharged within 6 months. Statistical analysis was performed by SPSS13.0 (SPSS Inc., Chicago, IL). Comparisons between conventional ORIF group and MIPPO group were performed using the $t$-test, and $p<0.05$ was considered statistically significant.

\section{Results}

Characteristics of the 36 patients and statistical results are displayed in Table 2 . No nerve and vascular injury or nonunion was noticed in all the 36 patients. Complications such as incisional infection, pneumonia and decubitus were cured before the patients were discharged from the hospital. The indexes of NEER score, ConstantMurley score, length of operation and intraoperative blood loss in MIPPO group were better than those in ORIF group $(p<0.05)$. Meanwhile two groups showed no significant difference in the statistical results of VAS and union time. To determine correlations of the NEER type, BMI and surgical method with the therapeutic outcome, all patients were divided into subgroups according to the NEER type (II or III) (Table 3 ) or BMI $(\geq 26.0$ or $<26.0)$ (Table 4) (Fig. 2).

It was found that both NEER type II and III had favorable impact on intraoperative blood loss. In addition, Constant-Murley score, NEER score, length of operation and SF36 score were better in NEER type III patients of

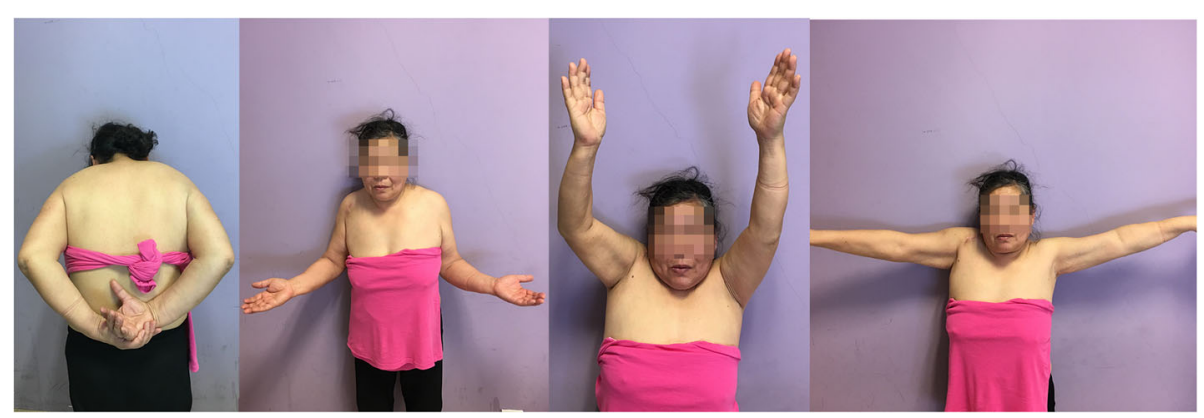

Fig. 2 At the 6-month follow-up, the patient had a good shoulder function. The 6-month constant score was 90 
Table 2 Follow-up data of the patients

\begin{tabular}{|c|c|c|c|c|c|}
\hline Characteristic & & Value & MIPPO group & ORIF group & $P$ value \\
\hline Constant-Murley score & Average $\pm S D$ & $87.8 \pm 1.9$ & $88.8 \pm 1.0$ & $86.9 \pm 2.1$ & 0.001 \\
\hline NEER score & Average $\pm S D$ & $86.5 \pm 2.2$ & $87.4 \pm 1.2$ & $85.7 \pm 2.6$ & 0.019 \\
\hline Intraoperative blood loss(ML) & Average $\pm S D$ & $137.7 \pm 22.0$ & $129.2 \pm 17.8$ & $145.3 \pm 23.0$ & 0.026 \\
\hline length of operation (minutes) & Average $\pm S D$ & $57.8 \pm 8.1$ & $53.6 \pm 7.3$ & $61.4 \pm 7.0$ & 0.002 \\
\hline Union time(months) & Average $\pm S D$ & $4.5 \pm 1.0$ & $4.5 \pm 1.1$ & $4.5 \pm 1.0$ & 0.873 \\
\hline $\begin{array}{l}\text { VAS(Visual Analogue Score(0-10):indicates } \\
\text { pain from minimum to maximum.) }\end{array}$ & Average $\pm S D$ & $3.1 \pm 1.3$ & $3.1 \pm 1.3$ & $3.2 \pm 1.3$ & 0.726 \\
\hline The short form (36) health survey. & Average $\pm S D$ & $125.6 \pm 9.1$ & $129.4 \pm 7.8$ & $122.3 \pm 8.9$ & 0.017 \\
\hline Complications & & & $\begin{array}{l}\text { Incision infection(1); } \\
\text { pneumonia(1) }\end{array}$ & $\begin{array}{l}\text { Incision infection(2); } \\
\text { decubitus(1) }\end{array}$ & \\
\hline
\end{tabular}

MIPPO group as compared with the conventional ORIF group $(P<0.05)$, suggesting that the prognosis in NEER type III patients may be better than that in NEER type III patients of the same MIPPO group (Table 3). Surprisingly, in patients with $\mathrm{BMI}<26.0$, there was no significant difference in Constant-Murley score, NEER score, intraoperative blood loss, length of operation and SF36 score between MIPPO and ORIF groups, while the difference was significant in patients with $\mathrm{BMI}>26.0$ (Table 4), suggesting that MIPPO technique may have better effects in over-weight individuals.

\section{Discussion}

MIPPO through the deltoid-pectoralis approach seems superior to conventional ORIF through the deltoid-pectoralis approach in the treatment of PHF in elderly patients in terms of Constant-Murley score, NEER score, intraoperative blood loss, length of operation and SF36 score. The application of MIPPO in elderly patients can not only decrease intraoperative injury and complications but avoid damage to blood supply of the deltoid muscle and axillary nerve.

To explore possible factors influencing the application of MIPPO technique, we also included the NEER type and BMI into statistical analysis. As described above, the prognosis was relatively better in patients over 65 years or with NEER type III or BMI index > 26.0. It seems that NEER type III and over-weight patients who were likely to have a worse prognosis [14] may acquire a relatively better outcome though MIPPO versus conventional ORIF, especially in patients with more complex PHF or those with a poor general condition.

But we found no significant difference in union time between the two groups. Some previous studies $[16,17]$ reported that MIPPO may prolong the union time in patients with humeral shaft fractures. We think that one of the possible explanations is that compared with the proximal humerus, the humeral shaft receives less blood supply, and thus sufficient blood supply plays a bigger role in fracture union in humeral shaft fractures than that in PHF. Therefore, MIPPO offers a better effect on union time in humeral shaft fractures, knowing that it is able to decrease soft tissue and vascular injury and increase blood supply in fracture union. However, this hypothesis needs to be confirmed in more cases. Compared with the deltoid-splitting approach reported in previous studies [4, 11, 14, 17], we think that the damage to blood supply could be dimished by protecting the integrity of the deltoid muscle to help bone healing and avoid damage to the axillary nerve in MIPPO.

Table 3 Demographics of statistical data of subgroup by NEER type

\begin{tabular}{|c|c|c|c|c|c|c|}
\hline \multirow[t]{2}{*}{ Characteristic } & \multicolumn{3}{|l|}{ NEER type II } & \multicolumn{3}{|l|}{ NEER type III } \\
\hline & MIPPO & ORIF & $P$ value & MIPPO & ORIF & $P$ value \\
\hline Constant-Murley score & $88.4 \pm 0.7$ & $87.1 \pm 2.7$ & 0.231 & $89.2 \pm 1.0$ & $86.8 \pm 1.8$ & 0.001 \\
\hline NEER score & $87.3 \pm 0.7$ & $86.6 \pm 2.6$ & 0.494 & $87.4 \pm 1.5$ & $85.2 \pm 2.6$ & 0.030 \\
\hline Intraoperative blood loss(ML) & $131.0 \pm 12.3$ & $148.3 \pm 21.1$ & 0.070 & $127.7 \pm 22.2$ & $143.6 \pm 24.8$ & 0.145 \\
\hline length of operation (minutes) & $55.3 \pm 7.9$ & $59.9 \pm 6.5$ & 0.245 & $52.2 \pm 6.8$ & $62.3 \pm 7.4$ & 0.005 \\
\hline Union time(months) & $4.5 \pm 1.4$ & $4.9 \pm 1.1$ & 0.595 & $4.4 \pm 0.9$ & $4.3 \pm 0.9$ & 0.779 \\
\hline VAS & $3.8 \pm 1.0$ & $3.6 \pm 1.1$ & 0.755 & $2.4 \pm 1.2$ & $3.0 \pm 1.3$ & 0.345 \\
\hline SF36 & $125.8 \pm 9.6$ & $122.6 \pm 6.2$ & 0.469 & $132.6 \pm 4.1$ & $122.1 \pm 10.5$ & 0.011 \\
\hline
\end{tabular}


Table 4 Demographics of statistical data of subgroup by BMI index

\begin{tabular}{|c|c|c|c|c|c|c|}
\hline \multirow[t]{2}{*}{ Characteristic } & \multicolumn{3}{|l|}{$\mathrm{BMl}<26.0$} & \multicolumn{3}{|l|}{$\mathrm{BMI} \geq 26.0$} \\
\hline & MIPPO & ORIF & $P$ value & MIPPO & ORIF & $P$ value \\
\hline Constant-Murley score & $89.1 \pm 0.69$ & $86.7 \pm 2.31$ & 0.01 & $88.6 \pm 1.1$ & $87.1 \pm 1.9$ & 0.048 \\
\hline NEER score & $87.7 \pm 1.25$ & $86.0 \pm 2.98$ & 0.17 & $87.1 \pm 1.1$ & $85.3 \pm 2.3$ & 0.043 \\
\hline Intraoperative blood loss(ML) & $118.1 \pm 16.3$ & $135.2 \pm 16.5$ & 0.052 & $137.0 \pm 14.9$ & $156.6 \pm 24.9$ & 0.052 \\
\hline length of operation (minutes) & $51.4 \pm 7.3$ & $60.4 \pm 8.2$ & 0.035 & $55.2 \pm 7.2$ & $62.6 \pm 5.7$ & 0.02 \\
\hline Union time(months) & $5.1 \pm 0.9$ & $4.6 \pm 1.1$ & 0.292 & $4.0 \pm 1.1$ & $4.4 \pm 0.9$ & 0.336 \\
\hline VAS & $2.5 \pm 1.6$ & $2.8 \pm 1.2$ & 0.745 & $3.4 \pm 1.0$ & $3.7 \pm 1.2$ & 0.603 \\
\hline SF36 & $128.3 \pm 11.4$ & $125 \pm 8.1$ & 0.495 & $130.1 \pm 4.6$ & $119.2 \pm 9.3$ & 0.004 \\
\hline
\end{tabular}

Avoiding damage to the deltoid muscle and minimizing the incision, especially in overweight patients, will facilitate early post-operative exercise [2-4]. Shortening the bedridden time and early exercise will decrease the incidence of complications such as DVT, pneumonia and delayed union, and help the recovery of shoulder joint function $[1,10]$.

Before clinical study, the attempts on NEER type IV fractures on models and animals all turned failed due to the difficulties of satisfied reduction and fixation. Therefore, in this study, we set the inclusion criteria for NEER type II and III. With the currently available surgical devices and intraoperative imaging systems, it seems impossible to implement reduction and fixation through a $5-\mathrm{cm}$ incision. But we can predict that with the wide use of MIPPO technique and evolution of the surgical devices, the MIPPO technique will be applicable to NEER type IV.

\section{Conclusion}

MIPPO through the deltoid-pectoralis approach seems superior to conventional ORIF through the deltoidpectoralis approach in the treatment of PHF in elderly patients in terms of Constant-Murley score, NEER score, intraoperative blood loss, length of operation and SF36 score.

\section{Limitations}

Due to the limited hospital capacity and research time, we only included 36 cases in the present study and followed them up for 4-24 months, which prevented us from obtaining absolute evidence to confirm the priority of the MIPPO technique. In addition, some older patients withdrew from the study because of severe systemic diseases, which reduced the mean age of the included patients $(64.0+5.8$ years $)$. Therefore, more clinical trials are needed to confirm the applicability of MIPPO to patients with severe systemic diseases.

\section{Acknowledgements}

We would like to acknowledge the reviewers for their helpful comments on this paper. Thanks to Dr. Nan Lu for helping perform the operations.
Availability of data and materials

All the data used in this article was collected from the patients and cannot be shared for privacy.

Funding

No funding has been received for this study.

\section{Authors' contributions}

All authors were involved in drafting the article or revising it critically for important intellectual content. LZ had full access to all the data in the study and took responsibility for the integrity of the data and the accuracy of data analysis. Study conception and design: LZ, PY, LZ, AMC. Acquisition of data: LZ, PY, LZ. Analysis and interpretation of data: LZ, PY, LZ. All authors read and approved the final manuscript. AM C and $L Z$, LZ performed the operations. All authors above have read this manuscript and approved for this final version.

\section{Competing interests}

We have no conflict of interest concerning the materials or methods used in this study or the findings specified in this article. The authors have no personal financial or institutional interest in any of the drugs, materials, or devices described in this article. Dr. zhao has full access to all the data in the study and claims responsibility for the accuracy of these data. The authors declare that they have no competing interests.

\section{Consent for publication}

The patient featured in Figs. 1 and 2 has been informed of this study and consented the publication.

Ethics approval and consent to participate

All patients have been fully informed the contents of this study, consented to participate in this study and signed informed consents form. This study was approved by the Medical Ethics Committee of the Second Military Medical University of Shanghai.

\section{Publisher's Note}

Springer Nature remains neutral with regard to jurisdictional claims in published maps and institutional affiliations.

Received: 21 December 2016 Accepted: 27 April 2017

Published online: 12 May 2017

\section{References}

1. Demirhan M, Kilicoglu O, Altinel L, Eralp L, Akalin Y. Prognostic factors in prosthetic replacement for acute proximal humerus fractures. J Orthop Trauma. 2003:17:181-8. discussion 188-189.

2. Aguado HJ, Mingo J, Torres M, Alvarez-Ramos A, Martín-Ferrero MA Minimally invasive polyaxial locking plate osteosynthesis for 3-4 part proximal humeral fractures: our institutional experience. Injury. 2016;47 Suppl 3:S22-8.

3. Koljonen PA, Fang C, Lau TW, Leung F, Cheung NW. Minimally invasive plate osteosynthesis for proximal humeral fractures. J Orthop Surg (Hong Kong). 2015;23:160-3. 
4. Chen $\mathrm{H}, \mathrm{Hu} X$, Tang $H$, Yang G, Xiang M. Minimal invasive percutaneous osteosynthesis for elderly valgus impacted proximal humeral fractures with the PHILOS. Biomed Res Int. 2015;2015:971216.

5. Kannus P, Palvanen M, Niemi S, Parkkari J, Järvinen M, Vuori I. Osteoporotic fractures of the proximal humerus in elderly Finnish persons: sharp increase in 1970-1998 and alarming projections for the new millennium. Acta Orthop Scand. 2000;71:465-70.

6. Neuhaus V, Bot AG, Swellengrebel $\mathrm{CH}$, Jain NB, Warner JJ, Ring DC. Treatment choice affects inpatient adverse events and mortality in older aged inpatients with an isolated fracture of the proximal humerus. J Shoulder Elbow Surg. 2014;23:800-6.

7. Horak J, Nilsson BE. Epidemiology of fracture of the upper end of the humerus. Clin Orthop Relat Res. 1975;(112):250-253.

8. Palvanen M, Kannus P, Niemi S, Parkkari J. Update in the epidemiology of proximal humeral fractures. Clin Orthop Relat Res. 2006:442:87-92.

9. Court-Brown CM, Garg A, McQueen MM. The epidemiology of proximal humeral fractures. Acta Orthop Scand. 2001;72:365-71.

10. Kralinger F, Schwaiger R, Wambacher M, Farrell E, Menth-Chiari W, Lajtai G, et al. Outcome after primary hemiarthroplasty for fracture of the head of the humerus. A retrospective multicentre study of 167 patients. J Bone Joint Surg Br. 2004;86:217-9.

11. Resch H, Povacz P, Fröhlich R, Wambacher M. Percutaneous fixation of three- and four-part fractures of the proximal humerus. J Bone Joint Surg Br. 1997;79:295-300

12. Mittlmeier TW, Stedtfeld HW, Ewert A, Beck M, Frosch B, Gradl G. Stabilization of proximal humeral fractures with an angular and sliding stable antegrade locking nail (Targon PH). J Bone Joint Surg Am. 2003;85-A Suppl 4:136-46.

13. Fankhauser F, Boldin C, Schippinger G, Haunschmid C, Szyszkowitz R. A new locking plate for unstable fractures of the proximal humerus. Clin Orthop Relat Res. 2005;430:176-81.

14. Maier D, Jäger M, Strohm PC, Südkamp NP. Treatment of proximal humeral fractures - a review of current concepts enlightened by basic principles. Acta Chir Orthop Traumatol Cech. 2012;79:307-16.

15. Zhou ZB, Gao YS, Tang MJ, Sun YQ, Zhang CQ. Minimally invasive percutaneous osteosynthesis for proximal humeral shaft fractures with the PHILOS through the deltopectoral approach. Int Orthop. 2012;36:2341-5.

16. Esmailiejah AA, Abbasian MR, Safdari F, Ashoori K. Treatment of humeral shaft fractures: minimally invasive plate osteosynthesis versus open reduction and internal fixation. Trauma Mon. 2015;20:e26271.

17. Brunner A, Thormann S, Babst R. Minimally invasive percutaneous plating of proximal humeral shaft fractures with the Proximal Humerus Internal Locking System (PHILOS). J Shoulder Elbow Surg. 2012;21:1056-63.

18. Ortmaier R, Filzmaier $V$, Hitzl W, Bogner R, Neubauer $T$, Resch $H$, et al. Comparison between minimally invasive, percutaneous osteosynthesis and locking plate osteosynthesis in 3-and 4-part proximal humerus fractures. BMC Musculoskelet Disord. 2015;16:297.

19. Oh HK, Cho DY, Choo SK, Park JW, Park KC, Lee Jl. Lessons learned from treating patients with unstable multifragmentary fractures of the proximal humerus by minimal invasive plate osteosynthesis. Arch Orthop Trauma Surg. 2015;135:235-42.

20. Lin T, Xiao B, Ma X, Fu D, Yang S. Minimally invasive plate osteosynthesis with a locking compression plate is superior to open reduction and internal fixation in the management of the proximal humerus fractures. BMC Musculoskelet Disord. 2014;15:206.

21. Wang ZH, Deng D, Chen LQ, Zhang WK, Yan HB, Chen XY, et al. Casecontrol studies on therapeutic effects of combined methods of minimally invasive percutaneous proximal humerus locked osteosynthesis plate with injectable bone for the treatment of proximal humerus fractures in elderly patients. Zhongguo Gu Shang. 2013;26:404-7.

22. Bachelier F, Pizanis A, Schwitalla J, Pohlemann T, Kohn D, Wirbel R. Treatment for displaced proximal humerus fractures: comparison of interlocking plate fixation versus minimal invasive techniques. Eur J Orthop Surg Traumatol. 2014;24:707-14

23. Kanthimathi B, Narayanan V. Minimal invasive plate osteosynthesis (MIPO) technique using anterolateral approach for treating closed proximal humerus fracture. Malays Orthop J. 2012;6:25-9.

24. Rancan M, Dietrich M, Lamdark T, Can U, Platz A. Minimal invasive long PHILOS ${ }^{\oplus}$-plate osteosynthesis in metadiaphyseal fractures of the proximal humerus. Injury. 2010;41:1277-83.
25. Röderer G, Erhardt J, Graf M, Kinzl L, Gebhard F. Clinical results for minimally invasive locked plating of proximal humerus fractures. J Orthop Trauma. 2010;24:400-6.

26. Rouleau DM, Laflamme GY, Berry GK, Harvey EJ, Delisle J, Girard J. Proximal humerus fractures treated by percutaneous locking plate internal fixation. Orthop Traumatol Surg Res. 2009;95:56-62.

27. Acklin YP, Jenni R, Walliser M, Sommer C. Minimal invasive PHILOS $\left({ }^{(}\right)$-plate osteosynthesis in proximal humeral fractures. Eur J Trauma Emerg Surg. 2009:35:35-9.

28. Gavaskar AS, Muthukumar S, Chowdary N. Biological osteosynthesis of complex proximal humerus fractures: surgical technique and results from a prospective single center trial. Arch Orthop Trauma Surg. 2010;130:667-72.

\section{Submit your next manuscript to BioMed Central and we will help you at every step:}

- We accept pre-submission inquiries

- Our selector tool helps you to find the most relevant journal

- We provide round the clock customer support

- Convenient online submission

- Thorough peer review

- Inclusion in PubMed and all major indexing services

- Maximum visibility for your research

Submit your manuscript at www.biomedcentral.com/submit
) Biomed Central 